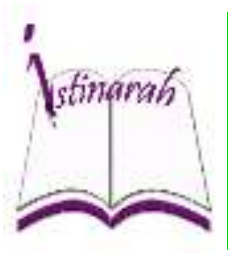

Istinarah: Riset Keagamaan, Sosial dan Budaya, Vol 1 (2), Desember 2019

ISSN : --------- (Print) .............. (Online $)$

Tersedia online di http://ecampus.iainbatusangkar.ac.id/ojs/index.php/istinarah/index

\title{
Opini Masyarakat Tentang Akhlak Mahasiswa IAIN Batusangkar
}

\author{
Riza Hendrayani *) \\ Institut Agama Islam Negeri \\ Batusangkar \\ Sumatera Barat, Indonesia \\ E-mail: \\ rezadelfano8@gmail.com
}

\section{Eliwatis}

Institut Agama Islam Negeri

Batusangkar.

Sumatera Barat, Indonesia

Email:

Eliwatis@iainbatusangkar.ac.id

\section{Oktri Permata Lani}

Institut Agama Islam Negeri

Batusangkar.

Sumatera Barat, Indonesia

Email:

blue9heart@yahoo.com

*) Corresponding Author

\begin{abstract}
Abstrak: Permasalahan dalam tulisan ini adalah bagaimana opini masyarakat Jorong Kubu Rajo tentang akhlak mahasiswa dalam pergaulan, opini masyarakat Jorong Kubu Rajo tentang akhlak mahasiswa dalam berkomunikasi dan opini masyarakat Jorong Kubu Rajo tentang akhlak mahasiswa dalam berpakaian. Penelitian ini menggunakan metode deskriptif kualitatif yaitu, penelitian yang bermaksud untuk memahami fenomena tentang apa yang dialami oleh subjek penelitian misalnya, perilaku, persepsi, motivasi, tindakan, secara holistik, dan dengan cara deskripsi dalam bentuk kata-kata dan bahasa, pada suatu konteks khusus yang alamiyah dan dengan memanfaatkan berbagai metode alamiyah. Penelitian ini adalah Penelitian dengan menggunakan teknik pengumpulan data dengan wawancara dan dokumentasi. Analisis data menggunakan analisis Miles \& Huberman. Dari penelitian ini ditemukan bahwa citra mahasiswa IAIN Batusangkar khususnya pendatang dari luar Tanah Datar memiliki citra yang negatif menurut opini/pendapat masyarakat Jorong Kubu Rajo baik dari segi pergaulan, komunikasi, adab berpakaian.
\end{abstract}

Abstract: The problem in this script is how Jorong Kubu Rajo's public opinion about student morals in society, Jorong Kubu Rajo's community opinion about student morals in communication and Jorong Kubu Rajo's community opinion about student morals in dress. This study uses descriptive qualitative methods, namely research that intends to understand the phenomena about what is experienced by research subjects, for example, behavior, perception, motivation, action, holistically, and by means of descriptions in the form of words and language, in a particular context natural and by utilizing various natural methods. This research is a study using data collection techniques with interviews and documentation. Data analysis using Miles \& Huberman analysis. From this study it was found that the image of Batusangkar IAIN students, especially migrants from outside Tanah Datar had a negative image according to the opinions / opinions of the people of Jorong Kubu Rajo both in terms of association, communication, and dress.

\section{Kata Kunci : Opini Masyarakat, Akhlak, Komunikasi}

\section{PENDAHULUAN}

Kehidupan manusia tidak akan lepas dari orang lain, karena manusia merupakan makhluk sosial yang 
senantiasa ingin berhubungan dengan manusia yang lainnya. Tanpa adanya peran dan bantuan dari orang lain, maka keberlangsungan hidup akan terganggu. Proses berhubungan dengan orang lain inilah yang membentuk kehidupan bermasyarakat.

Dalam bermasyarakat, banyak halhal yang perlu diketahui oleh setiap individu. Manusia yang jumlahnya lebih dari seorang, tentu harus mempunyai aturan-aturan yang dapat memisahkan hak dan kewajiban masing-masing orang yang dapat membentuk hubungan sosial antara seseorang dengan orang lain tersebut tetap berjalan dengan kondusif.

Opini adalah tanggapan aktif terhadap rangsangan, tanggapan yang disusun melalui interpretasi personal yang diturunkan dan turut membentuk citra, setiap opini merefleksi organisasi yang kompleks yang terdiri atas tiga komponen yaitu kepercayaan, nilai, dan pengharapan.

Masyarakat merupakan manusia yang senantiasa berhubungan (berinteraksi) dengan manusia lain dalam suatu kelompok (Setiadi dalam Bambang Tejokusumo, 2014: 38). Kehidupan masyarakat yang selalu berubah (dinamis) merupakan sesuatu yang tidak dapat dihindari. Manusia sebagai mahluk sosial selalu membutuhkan manusia lainnya untuk memenuhi kebutuhannya, sebuah keniscayaan manusia bisa hidup secara individual dalam lingkungannya.

Fenomena yang terjadi di lapangan opini masyarakat secara umum dapat terbentuk dari berbagai faktor antara lain latar belakang budaya (kebiasaan dan adat istiadat yang dianut seseorang atau masyarakat), pengalaman masa lalu, nilai-nilai yang dianut (moral,etika dan keagamaan yang dianut atau nilai-nilai yang berlaku dalam masyarakat).

Akhlak merupakan suatu yang penting selain itu akhlak juga termasuk dalam faktor pembentukan opini. Akhlak adalah suatu sikap mental atau keadaan jiwa yang mendorongnya untuk berbuat tampa berfikir dan pertimbangan. Sementara tingkahlaku manusia terbagi menjadi dua unsur, yakni unsur watak naluriah dan unsur kebiasaan dan latihan (ibnu Maskawih dalam Reni Susanti, 2015:2). Sedangkan menurut Reni Susanti akhlak adalah suatu yang sudah mendarah daging dalam diri seseorang, 
yang merupakan dorongan dari dalam jiwa seseorang. Artinya akhlak itu adalah sikap atau perilaku seseorang baik itu merupakan perbuatan baik atau perbuatan buruk. Dengan kata lain akhlak adalah keadaan jiwa yang mendorong timbulnya perbuatanperbuatan secara spontan. Sikap jiwa atau keadaan jiwa seperti ini terbagi menjadi dua bagian: ada yang berasal dari watak (bawaan) atau fitrah sejak kecil dan ada pula yang berasal dari kebiasaan latihan. Dengan demikian manusia dapat berusaha mengubah watak kejiwaan pembawaan fitrahnya dari yang tidak baik menjadi baik (2015: 6).

Berdasarkan obvservasi awal yang telah peneliti lakukan kepada ibuk Yelni yang tinggal di Lima Kaum tepatnya di Jorong kubu Rajo beliau mengatakan bahwa akhlak mahasiswa yang tinggal di jorong kubu rajo sangat mengecewakan karena mahasiswa yang diharapkan dapat menjadi panutan bagi masyarakat banyak malah mencerminkan perilaku yang tidak baik dan tidak layak untuk dijadikan figur. Seperti halnya, tidak mengucapkan salam ketika bertamu maupun ketika berpapasan, sering mengucapkan kata-kata kotor, sering melakukan perbuan ghibah dan mengadu domba antar sesama, begitu juga gaya berpakaian bagi kaum wanita yang tidak mencerminkan sebagai seorang mahasiswi islami, bagi kaum laki-laki masih saja ngumpul-ngumpul pada saat waktu sholat sudah masuk dan bermain koa (kartu kuning).

Dalam berakhlak mahasiswa IAIN Batusangkar sebaiknya mencerminkan akhlak yang baik, akan tetapi itu tidak sesuai dengan yang diharapkan. Karena akhlak mahasiswa IAIN Batusangkar masih menyimpang dari norma-norma agama seperti: menghalalkan segala cara untuk meraih sesuatu yang menjadi keinginannya, tidak peduli dengan aturan yang ada baik agama, pemerintah maupun masyarakat, mudah mengabaikan amalan ibadah, selalu mengajak berbuat kearah yang negatif kepada siapapun, tidak memperhatikan kepentingan orang lain, mudah mengucapakan kata-kata yang tidak baik dan tidak merasa malu melakukan perbuatan yang tidak seharusnya dilakukan.

\section{METODE}

Penelitian ini termasuk jenispenelitian deskriptif dengan 
menggunakan metode pendekatan kualitatif. Menurut Sugiyono (2013: 9) metode penelitian kualitatif adalah metode penelitian yang digunakan untuk meneliti pada kondisi obyek yang alamiah, sebagai lawannya adalah eksperimen. Menurut Bogdan dan Taylor dalam Lexy J. Moleong (2016: 4) mendefenisikan metodologi kualitatif sebagai prosedur penelitian yang menghasilkan data deskriptif berupa kata-kata tertulis atau lisan dari orang-orang dan perilaku yang dapat di amati. Sementara itu penelitian deskriptif adalah penelitian yang bermaksud untuk memahami fenomena tentang apa yang dialami oleh subjek penelitian misalnya, perilaku, persepsi, motivasi, tindakan, secara holistik, dan dengan cara deskripsi dalam bentuk kata-kata dan bahasa, pada suatu konteks khusus yang alamiyah dan dengan memanfaatkan berbagai metode alamiyah. Lexy J. Moleong (2016: 6).

Tujuan penelitian deskriptif kualitatif untuk memberikan gambaran, dan mendeskripsikan serta mengungkapkan bagaimana Opini Masyarakat Lima Kaum Jorong Kubu Rajo tentang Akhlak mahasiswa IAIN
Batusangkar.

Latar dan Waktu penelitian, peneliti memusatkan penelitian di IAIN Batusangkar, Waktu dalam penelitian ini pada rentang Agustus 2019.

Dalam penelitian kualitatif, yang menjadi instrumen kunci penelitian adalah peneliti itu sendiri. Menurut Sugiyono (2013: 22) instrumen utamanya adalah peneliti sendiri, namun setelah fokusnya jelas, maka kemungkinan akan dikembangkan instrumen penelitian sederhana, yang diharapkan dapat melengkapi data dan membandingkan dengan data yang ditemukan melalui observasi dan wawancara.

Sumber data dalam penelitian berupa data yang diambil langsung dari objek penelitian seperti Data primer (premier-sources), mencari data langsung ke lapangan agar data yang di dapat lebih akurat dengan sumber penelitian ini adalah ibu/bapak kos yang berada di Lima Kaum jorong kubu Rajo.

Selain itu peneliti juga menggunakan data Sekunder (secondary-sources), yaitu dengan mencari referensi berupa buku-buku 
dan jurnal yang berkaitan dengan Opini masyarakat tentang akhlak mahasiawa (Sugiyono, 2012:62).

Teknik pengumpulan data yang digunakan dalam penelitian kualitatif lebih menekankan pada jenis teknik observasi, yakni metode pengumpulan data dengancara mengamati perilaku dan lingkungan (sosial dan atau material) individu yang sedang diamati. (Gall, 2003: 254). Observasi yang peneliti lakukan melalui pengamatan secara langsung di lapangan untuk memperoleh data berkaitan dengan Opini Masyarakat Nagari Limo Kaum Jorong Kubu Rajo tentang akhlak mahasiswa IAIN Batusangkar.

Menurut Miles dan Huberman dalam Sugiyono (2013: 246), aktivitas analisis data yaitu data reduction atau reduksidata, di sini peneliti mengumpulkan, merangkum, memilih informasi- informasi yang pokok, memfokuskan pada informasi yang penting, di temukan tema dan polanya.

Dengan demikian data yang telah diredukasi akan memberikan gambaran yang lebih jelas.

Dalam penarikan kesimpulan peneliti melakukan interprestasi data sesuai dengan konteks permasalahan dari tujuan peneliti. Dari interprestasi yang dilakukan akan diperoleh kesimpulan dalam jawaban masalah penelitian. Dalam penelitian ini uji keabsahan data yang peneliti gunakan adalah dengan triangulasi.

Peneliti menggunakan triangulasi dengan sumber dan metode. Menurut Sugiyono (2013: 225-231) triangulasi dengan sumber berarti dengan cara menguji kredibilitas data dilakukan dengan cara mengecek data yang diperoleh dari Mahasiswa Mandahiliang di IAIN Batusangkar dengan menggunakan triangulasi data sebagai vasilidatas data, yang mana triangulasi ini bertujuan untuk menguji dan menjamin keabsahan data yang dilakukan dengan cara membandingkan data yang diperoleh dari beberapa sumber tentang data. Untuk menguji valid data yang akan peneliti dapatkan dari informan masyarakat Jorong Kubu Rajo Nagari Limo Kaum, di sini peneliti mengumpulkan keterangan dari beberapa informan masyarakat Jorong Kubu Rajo Nagari Limo Kaum.

\section{HASIL DAN PEMBAHASAN}

Berdasarkan hasil penelitian 
terkait dengan Opini masyarakat Jorong Kubu Rajo tentang akhlak mahasiswa dalam pergaulan, ada beberapa temuan:

Satu: Berdasarkan analisis data yang peneliti peroleh dari wawancara dan observasi terkait opini masyarakat Jorong Kubu Rajo tentang akhlak mahasiswa dalam pergaulan, peneliti menemukan ada beberapa hal mengenai opini masyarakat tentang akhlak mahasiswa dalam pergaulan. Pertama, tidak pandai tegur sapa kepada masyarakat ketika berpapasan di jalan. Kedua, suka memilih-milih teman yang berada dan membedabedakan teman. Ketiga, memasang muka masam ketika berpapasan dengan masyarakat. Keempat, tidak pandai mengucapkan salam ketika bertamu ke kosan teman. kelima, membiarkan teman yang lagi kesusahan.

Berdasarkan hasil temuan dan teori terkait dengan saling tolong menolong. Islam menganjurkan setiap orang Islam agar menjadikan tolong menolong sebagai ciri dan sifat dalam muamalah sesama mereka. Sebagian kelompok membantu sebagian kelompok lain dalam berbagai sektor kehidupan yang diperbolehkan oleh syari'at Islam. Islam memotivasi pemeluknya untuk meningkatkan kerja sama dalam segala amal kebaikan yang bermanfaat bagi pemeluknya didunia dan akhirat.

Menurut peneliti saling tolong menolong adalah sifat yang harus dimiliki oleh setiap orang dalam kehidupan bermasyarakat, karena sifat saling tolong menolong merupakan sifat mulia yang dianjurkan dalam syariat islam, islam memotivasi setiap manusia agar selalu berlomba-lomba dan bekerjasama dalam melakukan segala amal kebaikan di dunia dan akhirat.

Berdasarkan hasil wawancara dengan informan terkait Bagaimana Opini masyarakat Jorong Kubu Rajo tentang akhlak dalam pergaulan Mahasiswa IAIN Batusangkar didapatkan hasil bahwa, banyak dari mahasiswa yang melanggar aturan yang ada di Jorong Kubu Rajo, kurangnya sopan santun dari mahasiswa ketika berbicara dengan masyarakat disekitar tidak pandai tegur sapa terhadap masyarakat maupun kepada pemilik kos, banyak dari mahasiswa yang melanggar jam 
bertamu yang telah ditetapkan, pergi berdua dengan teman laki-laki yang bukan mahram nya bahkan ada juga yang melakukan hubungan yang tidak seharusnya dilakukan seperti hubungan suami istri.

Dua: Berdasarkan analisis data yang peneliti peroleh dari wawancara dan observasi terkait opini masyarakat Jorong Kubu Rajo tentang akhlak mahasiswa dalam berkomunikasi, peneliti menemukan ada beberapa hal mengenai opini masyarakat tentang akhlak mahasiswa dalam berkomunikasi. Pertama, tidak memiliki sopan santun dalam berbicara. Ketiga, , melakukan perbuatan menggunjingkan orang lain (ghibah). Keempat, mengucapkan katakata kotor yang tidak layak untuk diucapkan maupun untuk di dengar oleh orang lain.

Berdasarkan hasil temuan dan teori terkait dengan mengucapkan katakata kotor. Mengutuk dan sumpah serapah dalam kehidupan modern yang serba materiallistis sekarang ini seperti menjadi hal yang dianggap biasa. Seorang yang sempurna akhlaknya adalah orang yang paling jauh dari kata-kata kotor, kutukan, sumpah serapah dan kata-kata keji lainnya. Maka kita menghindari sikap mengejek, memperolok-olok dan memandang rendah orang yang berbicara.

Dosa mengumpat adalah dosa yang tidak akan diampuni oleh Allah meskipun pelakunya telah bertaubat, dia akan diampuni jika orang yang diumpat memberikan maaf. Namun apabila orang yang diumpat tidak memberi maaf, maka orang yang mengumpat tersebut masih berdosa dan akan dihukum nantinya diakhirat (Ernawati, 2017:100).

Menurut peneliti sifat yang suka mengucapkan kata-kata yang kotor merupaka sifat tercela yang dilarang oleh Allah karena bukan merupakan sifat orang yang beriman, Mengutuk dan sumpah serapah dalam kehidupan modern yang serba materiallistis sekarang ini seperti menjadi hal yang dianggap biasa. Seorang yang sempurna akhlaknya adalah orang yang paling jauh dari kata-kata kotor, kutukan, sumpah serapah dan kata-kata keji. kecelakaanlah bagi Setiap pengumpat lagi pencela. Dosa mengumpat adalah dosa yang tidak akan diampuni oleh Allah meskipun 
pelakunya telah bertaubat, dia akan diampuni jika orang yang diumpat memberikan maaf.

Berdasarkan hasil wawancara dengan informan terkait Bagaimana Opini Masyarakat Jorong Kubu Rajo tentang akhlak dalam berkomunikasi Mahasiswa IAIN Batusangkar didapatkan hasil bahwa, masih banyak mahasiswa yang berkata tidak sopan, tidak memiliki sopan santun dalam berbicara dengan teman sebaya, orang kecil dan orang yang lebih tua tidak memikirkan akibat dari perkataannya tersebut hanya mementingkan dirinya pribadi tidak memikirkan orang lain yang akan tersinggung dengan menggunakan kata-kata binatang dalam berbicara kepada teman.

Tiga: Berdasarkan analisis data yang peneliti peroleh dari wawancara dan observasi terkait opini masyarakat Jorong Kubu Rajo tentang akhlak mahasiswa dalam berpakaian, peneliti menemukan ada beberapa hal mengenai opini masyarakat tentang akhlak mahasiswa dalam berpakaian. Pertama, tidak memakai jilbab. Berdasarkan hasil temuan dan teori terkait dengan menutup tubuh bagian atas dengan tudung kepala yang seharusnya dipakai sesuai kehendak syarak yaitu untuk menutupi kepala dan rambut, tengkuk atau leher dan juga dada.

Kedua, masih banyak mahasiswa yang memakai pakaian yang ketat dan transparan. Berdasarkan hasil temuan dan teori terkait dengan memakai pakaian ketat dan transparan Pakaian yang tembus pandang dan ketat tidak memenuhi syarat menutup aurat. Rasulullah Saw. bersabda yang artinya : "Dua golongan ahli neraka yang belum pernah aku lihat ialah, satu golongan memegang cemeti seperti ekor lembu yang digunakan untuk memukul manusia dan satu golongan lagi wanita yang memakai pakaian tetapi telanjang dan meliuk liukkan badan juga kepalanya seperti bonggol unta yang tunduk. Mereka tidak masuk syurga dan tidak dapat mencium baunya walaupun bau syurga itu dapat dicium dari jarak yang jauh." (HR.Muslim).

Menurut peneliti dalam berpakaian harus menutup aurat terutama bagi perempuan yang sangat dianjurkan untuk menutup auratnya kecuali batasbatas yang telah ditentukan seperti muka dan telapak tangan yang telah 
diatur dalam syariat islam. Menutup aurat merupakan suatu hal yang dapat membuat kita yang menutupi aurat bisa terhindar dari hal-hal yang tidak diinginkan.

Berdasarkan hasil wawancara dengan informan terkait bagaimana opini masyarakat Jorong Kubu Rajo tentang akhlak dalam berpakaian didapatkan hasil bahwa, masih banyak mahasiswa ataupun mahasiswi yang melanggar adab dalam berpakain menurut syariat Islam hal ini dapat dilihat dari penjelasan informan diatas bahwa mahasiswa dan mahasiswi banyak yang melanggar adab dalam berpakaian seperti memakai baju ketat bagi perempuan, tidak mekakai jilbab saat keluar kosan, bergaya berlebihan tidak sesuai dengan kehidupan orang tuanya.

\section{KESIMPULAN DAN REKOMENDASI}

Berdasarkan analisis data tentang opini masyarakat Limo Kaum jorong Kubu Rajo tentang akhlak mahasiswa IAIN Batusangkar, diperoleh data sebagai berikut:

Pertama, opini masyarakat Limo Kaum jorong Kubu Rajo tentang akhlak pergaulan mahasiswa IAIN Batusangkar dalam pergaulan sesama mahasiswa maupun dengan masyarakat masih banyak dari mahasiswa yang melanggar aturan yang ada di Jorong Kubu Rajo, kurangnya sopan santun dari mahasiswa ketika berbicara dengan masyarakat disekitar tidak pandai tegur sapa terhadap masyarakat maupun kepada pemilik kos, banyak dari mahasiswa yang melanggar jam bertamu yang telah ditetapkan, pergi berdua dengan teman laki-laki yang bukan mahram nya bahkan ada juga yang melakukan hubungan yang tidak seharusnya dilakukan seperti hubungan suami istri.

Kedua, opini masyarakat Limo Kaum jorong Kubu Rajo tentang akhlak berkomunikasi mahasiswa dalam berkomunikasi yaitu masih banyak mahasiswa yang berkata tidak sopan, tidak memiliki sopan santun dalam berbicara dengan teman sebaya, orang kecil dan orang yang lebih tua tidak memikirkan akibat dari perkataannya tersebut hanya mementingkan dirinya pribadi tidak memikirkan orang lain yang akan tersinggung dengan menggunakan kata-kata binatang dalam berbicara kepada teman.

Ketiga, opini masyarakat Limo 
Kaum jorong Kubu Rajo tentang akhlak dalam berpakaian mahasiswa banyak dari mahasiswa yang melanggar aturan yang ada di Jorong Kubu Rajo yaitu masih banyak mahasiswa ataupun mahasiswi yang melanggar adab dalam berpakain menurut syariat islam, mahasiswa mahasiswi IAIN Batusangkar banyak yang melanggar adab dalam berpakaian seperti memakai baju ketat bagi perempuan, tidak mekakai jilbab saat keluar kosan, bergaya berlebihan tidak sesuai dengan kehidupan orang tuanya.

\section{REFERENSI}

Ahmadi, R. 2014. Metodologi Penelitian Kualitatif. Yogyakarta: Ar-Ruzz Media.

Bambang Tejokusumo, 2014, Dinamika Masyarakat Sebagai Sumber Belajar Ilmu Pengetahuan, Malang: Universitas Negeri Malang. Vol. 3 No. 1, 38-39

Moleong, L. J. (2000). Metodologi Penelitian Kualitatif. Bandung: PT Remaja Rosdakarya.

Noor, J. (2013). Metodologi Penelitian Skripsi, Tesis, Disertasi dan
Karya Ilmiah. Jakarta: Prenada Media Group.

Putera, N. (2012). Penelitian Kualitatif Proses \& Aplikasi. Jakarta Barat: Permata Putri.

Reni Susanti, 2015, Akhlak Tasawuf Dasar, Batusangkar: STAIN Batusangkar Press

Sugiyono. (2013). Metode Penelitian Kuantitatif Kualitatif dan $R \& D$. Cet. 18. Bandung: CV Alfabeta. , (2007). Metode Penelitian Pendidikan. Bandung: CV Alvabeta. 